suffer job loss, imprisonment, torture or expulsion. Furthermore, the loss of the academic members of a society will, unless they can maintain skills in exile and later return, permanently affect that society's future. Germany was a world leader in scholarship before Hitler but never fully recovered its academic position (Medawar \& Pyke, 2000); the USA, Australia, Canada and the UK all gained immeasurably, as to a lesser extent did others.

The number seeking CARA's help has quadrupled in the past 3 years and continues to grow. There has been a very significant increase in the number of medical and other healthcare professionals seeking refugee status in the UK and in other countries according to our own figures. This is partly because of the situation in Iraq, where healthcare professionals are still being targeted by extreme elements, despite media reports that the situation is improving. Several hundreds have been assassinated there since 2003, mostly because they have sought to continue their work in their specialty. Also, in Zimbabwe extremely harsh conditions apply and many have gone to South Africa and neighbouring countries after finding it impossible to practise.

Practical details of how an interested reader, of whom we hope you may be one, can support the work of CARA can be found on our website, www.academic-refugees.org. Psychiatrists across the globe can do much to assist this constituency of academic colleagues by speaking up against the stigmatisation of such refugees, supporting the correct view that they are and may increasingly become key local and global assets for a better future and, importantly, helping them to become re-established in their careers.

\section{References}

Medawar, J. \& Pyke, D. (2000) Hitler's Gift: Scientists Who Fled Nazi Germany. Richard Cohen Books.

Seabrook, J. (2008) The Refugee and the Fortress: Britain and the Flight from Tyranny. Palgrave-Macmillan.

\title{
Compulsory treatment in the community: concept and controversy
}

\section{David Skuse}

Behavioural and Brain Sciences Unit, Institute of Child Health, London WC1N 1EH, UK, email dskuse@ich.ucl.ac.uk

0 n 3 November 2008, new powers which allowed supervised community treatment, implemented by community treatment orders, came into effect in England. These orders were presaged by the Mental Health Act 2007 and contain specific conditions with which a patient must comply. The thinking behind the new orders was that patients in the community who are likely to be nonadherent to treatment could be treated under compulsion at an early stage in a relapsing phase of their illness, in order to prevent further relapse into serious illness, which could lead to their recurrent and compulsory admission to hospital. If patients who are to be treated in the community refuse to comply, they can be held in hospital against their will for up to 72 hours and forcibly treated. They cannot be forcibly compelled to accept treatment in the community. The legislation was controversial and was by no means universally supported. Some have argued that the motivation behind the introduction of new powers to allow 'compulsory treatment in the community' was more to assuage public anxiety about the potential threat to them caused by some people with mental health problems, a threat that is arguably in the public mind far greater than reality, than to provide a more liberal regime for the management of seriously ill psychiatric patients.

Since the introduction of this legislation, the Mental Health Act Commission reports that the use of community treatment orders has far exceeded official estimates. In fact, recent reports suggest mental health services are struggling to deal with the high demand: more than 1200 people in England had been made subject to compulsory treatment 5 months after the powers were introduced. There have been delays processing the new orders because of a shortage of psychiatrists appointed to provide second opinions, who are able to authorise them.

England is not the only country to have introduced the option of compulsory treatment in the community, and in this issue we discuss the experience of a range of countries from Europe (James Strachan), the Middle East (Moody Magdy Zaky) and the Antipodes (John Dawson). Controversies are discussed by each of these authors. One key issue concerns the infrastructure that is provided to support compulsory treatment in the community or, rather, the lack of it. Another is the exact configuration of people (professionals and kin) needed to authorise such treatment, to protect the rights of the patient from potential abuse. It is particularly interesting to read the experience of New Zealand, which has had a community treatment order scheme since 1992: it seems that psychiatrists and even patients find the scheme works well, and they broadly support it. In view of this happy state of affairs, those responsible for framing legislation in other countries would be advised to learn from the New Zealand experience. 